\title{
Problems encountered in treating one leprosy patient in a developing country: a case report
}

\author{
MARY S JOSEPH \& WISUT SUKEEPAISAN \\ CHAROEN \\ Nonsombun Leprosy Hospital, Khon Kaen, Thailand
}

Accepted for publication 27 January 1986

\begin{abstract}
Summary We describe multiple problems encountered in the management of 1 patient suffering from lepromatous leprosy in a developing country, and these include Type II lepra reaction, intercurrent infection, shortage of experienced colleagues to consult, laboratory shortcomings, and side-effects of chemotherapy. It is postulated that the development of pustular and acneiform skin lesions in our patient is a new and previously unreported side-effect of dapsone.
\end{abstract}

\section{Case history}

A 36-year-old Thai male had been treated for active lepromatous leprosy with dapsone for 1 year, and when first seen on 6 September 1983, he was receiving 100 $\mathrm{mg} /$ day. He had also been receiving prednisolone $20 \mathrm{mg} /$ day for almost the same period of time because of small skin eruptions in the form of papules and pustules, which he referred to as 'reaction'; he was unable to give exact details regarding the duration, etc., of these eruptions, but he could recollect that they appeared within a few days of starting dapsone and persisted almost continuously since then. There was associated burning sensation over the affected skin areas, and he also complained of frequent fever and myalgia. He was sent to this hospital because of the recent appearance of large erythematous painful nodules and necrotizing lesions associated with severe systemic symptoms in addition to the earlier papules and pustules.

\section{On examination}

The patient was febrile and looked ill. Cushingoid features including central obesity and 'mooning' of face were present. There were few large erythematous tender nodules, some of them ulcerating, suggestive of ENL. The face as well as 
both upper extremities were covered with numerous small $(1-2 \mathrm{~mm})$ papules and pustules, distributed bilaterally and symmetrically. Upper portions of chest and back also had similar lesions, but less in number, and most of them resembled acne; other parts of the body had an insignificant number of lesions. The patient looked moderately anaemic. There was no oedema of extremities. There was generalized lymphadenopathy, but the nodes in the left axilla were relatively very large and matted as well as tender. Bilateral epididymo-orchitis was present. There were no clinical abnormalities in heart, lungs or abdomen, and his urine was normal. Chest X-ray appeared normal. BI of smears was $4+$.

\section{Treatment}

Dapsone $100 \mathrm{mg} / \mathrm{day}$ was continued, and in addition he received clofazimine (Lamprene) $300 \mathrm{mg} /$ day, thalidomide $300 \mathrm{mg} /$ day, analgesics and hematinics. Prednisolone $20 \mathrm{mg} /$ day was continued, but was tapered off over the next 4 weeks.

\section{Progress}

The ENL and epididymo-orchitis subsided well within the next 2 weeks, but the small skin eruptions persisted, together with a continuous low-grade fever. By this time it was observed that these papules and pustules appeared in crops, individual lesions lasting 2 or 3 days, then subsided leaving hyperpigmented areas but no crusting or scarring. A few episodes of epistaxis occurred during his first few months in hospital.

In the 5th week after admission, when the patient was off prednisolone and thalidomide for a week, there was a recurrence of epididymo-orchitis, but ENL was absent. In addition he developed pain and tenderness involving the muscles of both thighs, and admitted having experienced similar episodes over the previous few months. We had observed, on admission, that there was moderate wasting of some thigh muscles, and he had a clumsy gait, but these findings were attributed to be part of a cushingoid syndrome secondary to prednisolone. Prednisolone was re-started with a dose of $30 \mathrm{mg} /$ day, and later was gradually tapered off. It was observed at this time that the fever, skin eruptions and muscle symptoms disappeared, along with signs of epididymo-orchitis, whenever the patient was on the larger doses of prednisolone, and as treatment progressed it was noted on many occasions that skin lesions and muscle symptoms reappeared whenever prednisolone was reduced to less than $20 \mathrm{mg} /$ day. On these grounds we ruled out the possibility of steroid acne and of steroid myopathy.

Lymph node biopsy (left axilla) in the 8th week after admission revealed changes of tuberculosis adenitis, so a 3-months course of anti-tuberculosis treatment was given consisting of rifampicin $600 \mathrm{mg} /$ day and 1 tablet of IT/day 
(each tablet consisting of isoniazid $300 \mathrm{mg}$ and thiacetazone $150 \mathrm{mg}$ ). The tuberculous lymph nodes subsided, but the pustular and acneiform skin lesions persisted. Pus from the lesions showed no growth on culture and VDRL was negative.

After 9 months of hospital treatment his condition was very pathetic, with pustules covering his face, upper extremities, and upper back, with very painful and tender thigh muscles which were remarkably wasted, causing a weak and clumsy gait, and continuous fever. There was no involvement of calf muscles, nor any sign of foot drop. Tendon reflexes were equivocal. At this time he was on dapsone $100 \mathrm{mg} /$ day, clofazimine $100 \mathrm{mg} /$ day, and hematinics. He had not received prednisolone for a few weeks. Because of the possibility that his skin lesions represented a hypersensitivity to dapsone, this drug was stopped, but clofazimine and hematinics were continued. Prednisolone was re-started in a dosage of $30 \mathrm{mg} /$ day. Within 2 weeks of stopping dapsone, remarkable improvement was noticed. There was no flaring up when the dosage of prednisolone was reduced, and in the 5 th week while on prednisolone $10 \mathrm{mg} / \mathrm{day}$, only an occasional pustule could be seen. It was also observed that on exposure to sunlight there was exaggeration of lesions associated with burning sensation.

Two months af ter stopping dapsone the patient was completely off prednisolone and was free from skin lesions. He was not febrile and feeling well, his gait had improved, and there was no pain or tenderness in thigh muscles, although wasting was unchanged. He was now given a trial dose of dapsone $100 \mathrm{mg}$. Five or 6 hours later he was febrile and complained of pain and burning sensation all over the body, but there were no skin lesions. Next morning, after about 20 hours,

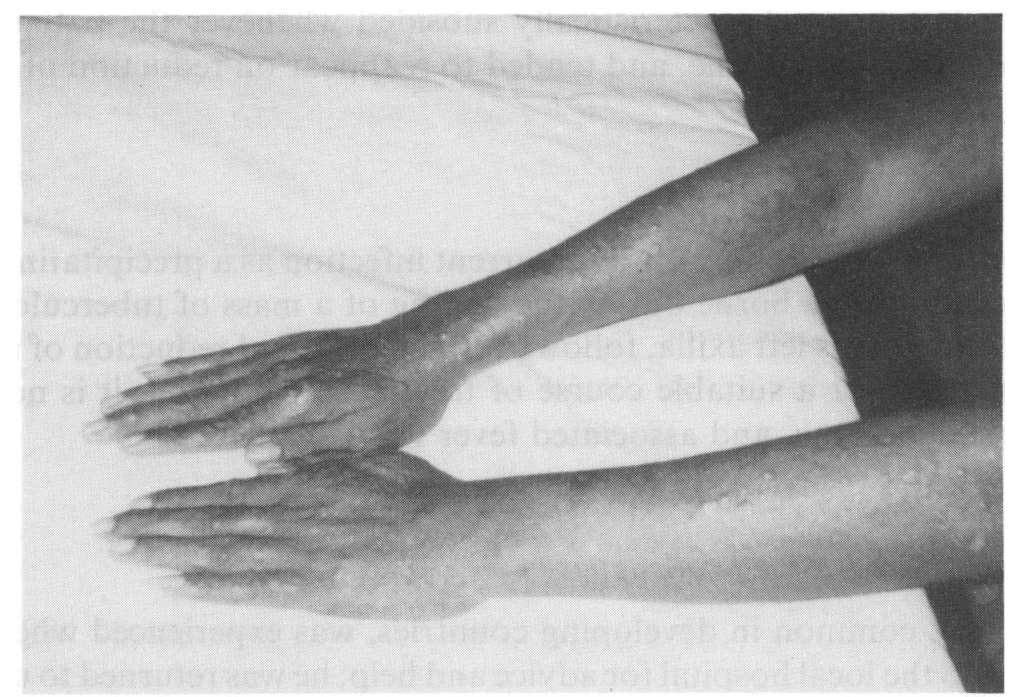

Figure 1. Bilateral papules and pustules on the forearms following a single trial dose of dapsone. 
there were numerous papules associated with severe itching and burning, and few pustules; lesions were mostly on face, upper extremities (Figure 1) and upper back. It was interesting to note that on intentional exposure to sun, there were fresh lesions and exaggeration of itching and burning over the involved areas. One more dose of dapsone was given on the next day, and many new papules and pustules appeared. No more dapsone was given and these symptoms subsided within 1 week after a short course of prednisolone. Thereafter he had no significant complaints and was discharged, one year after admission, on clofazimine $100 \mathrm{mg} / \mathrm{day}$. Two months later, at follow-up examination, he was feeling well, and appeared healthy and strong. Although his thigh muscles remained thin, he had no muscle pain or weakness. Affected skin areas looked hyperpigmented, but there was no pitting or scarring. Skin smears contained granular bacilli.

\section{Discussion}

This case emphasizes the multiplicity of problems which can be associated with the management of lepromatous leprosy in a developing country, and these can be described as follows:

\section{Type II reaction}

Manifestations of Type II reaction included bouts of ENL, sometimes becoming necrotic, moderate anaemia, epididymo-orchitis, myositis, epistaxis, and fever. These manifestations characteristically subsided whenever the patient was on higher doses of prednisolone, and tended to reappear on reduction of dosage to less than $20 \mathrm{mg} /$ day.

\section{Intercurrent infection}

The importance of searching for intercurrent infection as a precipitating cause of Type II reaction ${ }^{1}$ was borne out by the finding of a mass of tuberculous lymph nodes in the patient's left axilla, followed by an all-round reduction of reactional manifestations after a suitable course of treatment. However, it is noteworthy that the pustuloderma, and associated fever were unaffected.

\section{Shortage of experienced colleagues}

This problem, common in developing countries, was experienced when we sent our patient to the local hospital for advice and help; he was returned to us with the message that he had been given treatment for syphilis! 


\section{Laboratory shortcomings}

Another handicap when treating leprosy in a developing country is that requests for laboratory investigations may go unreported, or, if reports are received, they may be unreliable. We sent pus from the enlarged lymph nodes for AFB culture, and the sputum was examined at the hospital, but no reports were received. Our patient's $\mathrm{Hb}$ was reported to be $4.0 \mathrm{~g} \%$ on the first occasion, and $4.5 \mathrm{~g} \%$ on the second, results which we refused to accept as the patient did not appear to be profoundly anaemic. On the 3rd occasion we were informed that the $\mathrm{Hb}$ was $13 \mathrm{~g} \%$. The report on lymph node biopsy carried the diagnosis of 'lepromatous leprosy' in spite of the presence of 'masses of epithelioid cells, so we drew our own conclusions as to the true diagnosis of tuberculosis. It was because of laboratory unreliability that we omitted investigations such as differential white cell counts and liver function tests.

\section{Side-effects of Chemotherapy}

(a) Prednisolone. Our patient had signs of Cushingoid syndrome when first seen with moon face and central obesity.

(b) Dapsone. We propose that the pustuloderma was part of a hypersensitivity reaction to dapsone; not only was there associated fever and generalized lymphadenopathy, but there was a history of onset of symptoms a few days after commencing treatment with dapsone. Furthermore, there was a good response to prednisolone and to withdrawal of dapsone. Pustuloderma reappeared following a single trial dose of dapsone. These circumstantial evidences support a direct association between the drug and the skin manifestations. Drug reactions have a remarkable ability to mimic other diseases. They may take the form of vascular, eczematous, follicular, ulcerating, vegetating, gangrenous, furunculoid, carbunculoid, as well as pustular lesions. ${ }^{2}$ Hypersensitivity to drugs such as sulphonamides, iodides and bromides, is known to be among the non-infectious causes of pustular skin eruptions, ${ }^{3}$ and comparable cases have been reported with chloramphenicol, piperazine, pyrimethamine and frusemide. ${ }^{4} \mathrm{~A}$ recent report has incriminated carbamazepine,${ }^{5}$ and the authors suggest that pustuloderma can be induced by a drug-induced toxic erythema which has progressed to erythroderma, the inflammation of the skin being so intense that toxic pustulation occurs. Although a number of skin complications may occur as part of a hypersensitivity reaction to dapsone ${ }^{6,7}$ - exanthematous skin eruption, ${ }^{8,9}$ exfoliative dermatitis, ${ }^{10}$ toxic epidermal necrolysis, ${ }^{11}$ and Stevens-Johnson syndrome, ${ }^{12}$ - pustular and acneiform skin eruptions have not been described previously, although there is a report of a patient who developed papular and pustular skin lesions, later followed by exfoliative dermatitis. ${ }^{13}$

In the differential diagnosis of our patient's skin eruptions we must consider necrotic ENL (erythema necroticans), steroid acne, papulonecrotic tuberculids, and pustular syphilids. 
Necrotic ENL can be excluded because as mentioned earlier, the larger lesions suggestive of ENL as well as the epididymo-orchitis subsided completely while on treatment with prednisolone, thalidomide and high doses of clofazimine, whereas the small eruptions kept recurring even when the patient was on high doses of clofazimine for over 3 months, and when the lesions subsided with stoppage of dapsone, the patient was only on $100 \mathrm{mg}$ /day; moreover, these lesions showed no ulceration or crusting as do necrotizing ENL. Steroid acne can be ruled out as the lesions subsided with higher doses of prednisolone, and vice versa. Papulonecrotic tuberculids were excluded when the lesions failed to respond to 3 months of antituberculosis treatment; moreover, tuberculid lesions are papules and nodules which undergo central necrosis, and heal spontaneously with pitted scarring. ${ }^{14}$ Normally, typical pustules are absent. Pustular syphilids are mainly on the trunk, forehead and extremities; pustules arise from red infiltrated bases, they involute slowly, resulting in a rather persistent crust-covered superficial ulceration. ${ }^{15}$ In our patient there was no ulceration, crusting or scarring, VDRL was nonreactive, and there was no response to anti-syphilis treatment.

The exaggeration of the cutaneous manifestations on exposure to sunlight could be due to a possible photoallergic and phototoxic effect of dapsone, since such adverse effects are known to be caused by many drugs including sulphonamides. ${ }^{16}$

\section{Acknowledgment}

We are very grateful to Dr W H Jopling for his kind help, assurance and support, especially for revising the typescript and providing additional ref erence materials. Our grateful thanks are due to $\mathrm{Dr} \mathrm{K}$ Ramanujam for supplying reference materials. Finally we thank our patient for bearing with us during the long period taken to establish the diagnosis.

\section{References}

1 Jopling WH. Handbook of Leprosy, 3rd edn. Management of lepra reaction. London: William Heinemann Medical Books Ltd, 1984, p. 97.

2 Domonkos AN, Arnold HL, Odom RB. Andrews' Diseases of the skin P, Clinical Dermatology, 7th edn. Drug reactions. Tokyo: W B Saunders Company, Igaku-Shoin/Saunders, 1982, p. 137.

${ }^{3}$ Fitzpatrick TB, Haynes HA. Harrison's Principles of Internal Medicine, 9 th edn. Skin lesions of general medical significance. Isselbacher-Adams-Braunwald-Petersdorf-Wilson. Tokyo: McGraw-Hill Kogakusha Ltd, 1980, p. 241.

${ }^{4}$ Macmillan AL. Generalised pustular Drug Rash. Dermatologica, 1973; 146: 285-91.

5 Staughton RCL, Harper JI, Rowland CME, McMichen H. Toxic Pustulo-derma-a new entity?. $J$ Roy Soc of Med, Supplement No. 4, 1984; 77: 6-8.

${ }^{6}$ Bryceson A, Pfaltzgraff RE. Leprosy, 2nd edn. Side effects of dapsone. Longman Inc. N.Y and associated companies, 1979, p. 45. 
7 Jopling WH. Side effects of antileprosy drugs in common use. Lepr Rev, 1983; 54: 261-70 and 1985; 56: 61-70.

${ }^{8}$ Kader Naina Mohamed. Hypersensitivity reaction to dapsone: report from Malaysia. Lepr Rev, 1984; 55: 385-9.

9 Tomecki KJ, Catalano CJ. Dapsone Hypersensitivity. Arch Dermatol, 1981; 117: 38-9.

${ }^{10}$ Sardari Lal, Garg BR. Sulfone induced exfoliative dermatitis and hepatitis. Lepr India, 1980; 52: 302-5.

11 Katoch K, Ramu G, Ramanathan U. Toxic epidermal necrolysis (Lyell syndrome): a case report. Lepr India, 1983; 55: 133-5.

12 Dutta RK. Erythema multiforme bullosum due to dapsone. Lepr India, 1980; 52: 306-9.

13 Ramanujam K, Ramu G. Toxic reactions to parent sulfone: report of four cases. Lepr India, 1968; 40: 1 .

${ }^{14}$ Domonkos AN, Arnold HL, Odom RB. Andrews' Diseases of the skin, Clinical Dermatology, 7th edn. Mycobacterial diseases. Tokyo: W B Saunders Company, Igaku-Shoin/Saunders, 1982, p. 415.

15 Domonkos AN, Arnold HL, Odom RB. Andrews' Diseases of the skin, Clinical Dermatology, 7th edn. Intermediate and late secondary syphilis. Tokyo: W B Saunders Company, Igaku-Shoin/ Saunders, 1982, p. 453.

${ }^{16}$ Madhukar A, Pathak, Fitzpatrick TB, Parrish JA. Harrison's Principles of Internal Medicine, 9th edn. Photosensitivity and other reactions to light. Isselbacher-Adams-Petersdorf-Wilson. Tokyo: McGraw-Hill Kogakusha Ltd, 1980, p. 255-62. 